\title{
Implementation and microbiological stability of dose- banded ganciclovir infusion bags prepared in series by a robotic system
}

Irene Krämer, Matteo Federici

Department of Pharmacy, University Medical Centre, Johannes Gutenberg-University Mainz, Mainz, Germany

\section{Correspondence to} Dr Irene Krämer, Department of Pharmacy, University Medical Center, Mainz 55122, Germany; irene.kraemer@ unimedizin-mainz.de

Received 2 September 2018 Revised 14 October 2018 Accepted 18 October 2018 Published Online First 26 November 2018

EAHP Statement 3: Production and Compounding.
A) Check for updates

(C) European Association of Hospital Pharmacists 2020. No commercial re-use. See rights and permissions. Published by BMJ.

To cite: Krämer I, Federici M. Eur J Hosp Pharm 2020;27:209-215.
ABSTRACT

Objectives The implementation of dose-banding (DB) in centralised, pharmacy-based cytotoxic drug preparation units allows the preparation of standardised doses in series. The aim of this study was to evaluate the feasibility of DB for the prescribing of ganciclovir (GV) infusion solutions and to investigate the microbiological stability of dose-banded, automatically prepared readyto-administer GV infusion bags by media-fill simulation tests and sterility tests.

Methods The frequency of prescription of GV doses was retrospectively analysed before and after implementing the DB scheme. Four dose-ranges or 'bands' and the corresponding standard doses (250, $300,350,400 \mathrm{mg}$ ) were identified. The maximum variance was set at $\pm 10 \%$ of the individually prescribed dose. The aseptic preparation of a series of GV infusion bags was simulated with double strength tryptic soy broth as growth medium and prefilled $0.9 \% \mathrm{NaCl}$ polyolefin infusion bags as primary packaging materials. The simulation process was performed with the APOTECAchemo robot on five consecutive days. In total, 50 infusion bags were filled, incubated and stored for 12 weeks at room temperature. The media-filled bags were visually inspected for turbidity after 2, 4, 8, 10 and 12 weeks. Following incubation, growth promotion tests were performed. During the simulation tests, airborne contamination was monitored with settle plates and microbial surface contamination with contact plates. Pooled sterility tests were performed for a series of 10 standard GV infusion bags after a 12-week storage period under refrigeration $\left(2^{\circ} \mathrm{C}-8^{\circ} \mathrm{C}\right)$.

Results After implementation of the DB scheme, about $60 \%$ of the prescribed GV doses were prepared as standard preparations by the robotic system. The number of different GV doses was reduced by $61.8 \%$ (76 vs 29 ). None of the 50 media-filled bags showed turbidity after a storage period of 12 weeks, indicating the absence of microorganisms. The environmental monitoring with settle/contact plates matched the recommended limits set for cleanroom Grade A zones, except in the loading area of the robot. Media fills used for the sterility tests remained clear during the incubation period, thereby revealing sterility. Positive growth promotion tests proved the process's reliability.

Conclusions A DB scheme for prescribing and preparation of standard GV infusion bags was successfully implemented. Microbiological tests of aseptic preparation of infusion bags in series by the APOTECAchemo robot revealed an adequate level of sterility and a well-controlled aseptic procedure. The sterility was maintained over extended storage periods, thereby encouraging extended beyond-use dating.

\section{INTRODUCTION}

Ganciclovir (GV) is indicated for the treatment of CMV disease in immunocompromised patients and prevention of CMV disease in patients with druginduced immunosuppression (for example, following organ transplantation or cancer chemotherapy). ${ }^{1}$ For induction treatment of CMV disease, $5 \mathrm{mg} / \mathrm{kg} \mathrm{GV}$ are given as an intravenous infusion over 1 hour, every 12hours for 14-21 days. For maintenance therapy, $5 \mathrm{mg} / \mathrm{kg} \mathrm{GV}$ may be given once daily for 7 days per week or $6 \mathrm{mg} / \mathrm{kg}$ once daily for 5 days per week. In patients with renal impairment, dose modifications according to the creatinine clearance are required. ${ }^{1} \mathrm{~A}$ table with the recommended doses for induction and maintenance treatment according to the estimated creatinine clearance $(\mathrm{eCrCl})^{1}$ is shown in figure 1 as part of our prescribing form.

$\mathrm{GV}$ is marketed as $500 \mathrm{mg}$ powder for concentrate for solution for infusion that is reconstituted in $10 \mathrm{~mL}$ of water for injection to achieve a concentration of $50 \mathrm{mg} / \mathrm{mL} \mathrm{GV}$. Prior to intravenous administration, the GV premix solution is to be diluted with $0.9 \%$ sodium chloride infusion solution. Since GV is considered a potential teratogen and carcinogen in humans, it should be handled as a hazardous drug. ${ }^{12}$ Moreover, reconstituted $\mathrm{GV}$ solutions are alkaline $(\mathrm{pH}$ 11). In order to prevent occupational exposure and to assure sterility of the ready-to-administer infusion solutions, patient individual GV-infusions are often prepared under aseptic conditions in pharmacy-based centralised cytotoxic drug preparation units. Annually about 2000 patient individual GV preparations are produced in the pharmacy department of the University Medical Centre Mainz (Germany). To manage the increasing workload and to optimise the capacity of the preparation unit, dose-banding (DB) of GV infusion solutions was considered. DB is a system whereby individually calculated doses of intravenous cytotoxic drugs are grouped within defined 'bands' (dose ranges) and predetermined standard doses (band midpoint) are prepared and dispensed. ${ }^{3}$ DB allows the preparation of standardised products in series and as stock, efficient automation of the preparation process by robotic systems, and quality control testing prior to administration. Key determinants for dose banding and pre-production of ready-to-use products are extended stability data and a reasonable turnover of the products. Further details regarding the major benefits and drawbacks of DB can be found in the literature. $^{3-8}$ There are no data about dose banding of GV to be found in the literature except the recently published hint by Guichard et al. ${ }^{9}$ 


\begin{tabular}{|c|c|c|c|c|c|c|c|c|}
\hline$\frac{1}{5}$ & $\begin{array}{r}\text { Unive } \\
\text { Johanne } \\
\text { D } \\
\text { Cytc }\end{array}$ & $\begin{array}{l}\text { rsity Hospital Cente } \\
\text { Gutenberg-Univer } \\
\text { partment of Pharm } \\
\text { toxic drugs preparatio }\end{array}$ & $\begin{array}{l}\text { of the } \\
\text { ty Mainz } \\
\text { cy } \\
\text { unit }\end{array}$ & Patient & 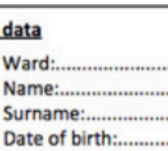 & 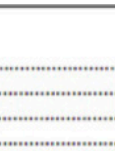 & 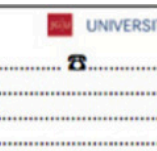 & smedizin. \\
\hline \multicolumn{3}{|c|}{ Body weight [kg]: } & \multicolumn{2}{|c|}{ Creatinine Clearance } & \multicolumn{2}{|c|}{ Dose for induction therapy } & \multicolumn{2}{|c|}{ Dose for maintenance therapy } \\
\hline \multirow{2}{*}{\multicolumn{3}{|c|}{ 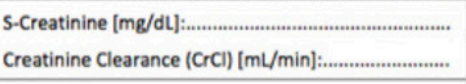 }} & \multicolumn{2}{|c|}{$\mathrm{CrCl} \geq 70 \mathrm{~mL} / \mathrm{min}$} & \multicolumn{2}{|c|}{$5 \mathrm{mg} / \mathrm{kg} \mathrm{q} 12 \mathrm{~h}$} & \multicolumn{2}{|c|}{$5 \mathrm{mg} / \mathrm{kg} / \mathrm{day}$} \\
\hline & & & \multicolumn{2}{|c|}{$\mathrm{CrCl} 50-69 \mathrm{~mL} / \mathrm{min}$} & \multicolumn{2}{|c|}{$2.5 \mathrm{mg} / \mathrm{kg} \mathrm{q} 12 \mathrm{~h}$} & \multicolumn{2}{|c|}{$2.5 \mathrm{mg} / \mathrm{kg} / \mathrm{day}$} \\
\hline \multirow{2}{*}{\multicolumn{3}{|c|}{ Diagnosis: }} & \multicolumn{2}{|c|}{$\mathrm{CrCl} 25-49 \mathrm{~mL} / \mathrm{min}$} & \multicolumn{2}{|c|}{$2.5 \mathrm{mg} / \mathrm{kg} / \mathrm{day}$} & \multicolumn{2}{|c|}{$1.25 \mathrm{mg} / \mathrm{kg} / \mathrm{day}$} \\
\hline & & & \multicolumn{2}{|c|}{$\mathrm{CrCl} 10-24 \mathrm{~mL} / \mathrm{min}$} & \multicolumn{2}{|c|}{$1.25 \mathrm{mg} / \mathrm{kg} / \mathrm{day}$} & \multicolumn{2}{|c|}{$0.625 \mathrm{mg} / \mathrm{kg} / \mathrm{day}$} \\
\hline \multirow{2}{*}{\multicolumn{3}{|c|}{$\begin{array}{l}\text { Dose modification: } \square \text { No } \square \text { Yes } \\
\text { Reason:-....................... }\end{array}$}} & \multicolumn{2}{|c|}{$\mathrm{CrCl}<10 \mathrm{~mL} / \mathrm{min}$} & \multicolumn{2}{|c|}{$1.25 \mathrm{mg} / \mathrm{kg} 3 \mathrm{x} /$ week* $^{*}$} & \multicolumn{2}{|c|}{ 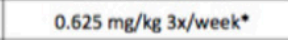 } \\
\hline & & & \multicolumn{2}{|c|}{ Haemodialysis } & \multicolumn{2}{|c|}{$5 \mathrm{mg} / \mathrm{kg} \mathrm{q} 48 \mathrm{~h}$} & \multicolumn{2}{|c|}{ - } \\
\hline \multicolumn{3}{|c|}{ 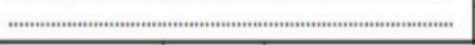 } & \multicolumn{6}{|c|}{ Pafter haemodialysis } \\
\hline $\begin{array}{c}\text { Date of } \\
\text { administration }\end{array}$ & $\begin{array}{c}\text { Therapy } \\
\text { day }\end{array}$ & $\begin{array}{c}\text { Drug } \\
\text { (INN-Nomenclature) }\end{array}$ & $\begin{array}{r}\text { Doses } \\
(\mathrm{mg} / \mathrm{kg} / \mathrm{ad}\end{array}$ & & Dose band & $\begin{array}{l}\text { Dose } \\
\text { [mg] }\end{array}$ & $\begin{array}{l}\text { Administration } \\
\text { frequency } \\
\text { (e.g. q12h) }\end{array}$ & $\begin{array}{c}\begin{array}{c}\text { Infusion } \\
\text { volume [mL] }\end{array}\end{array}$ \\
\hline \multirow{6}{*}{ 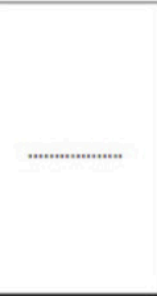 } & \multirow{6}{*}{................ } & \multirow{6}{*}{ Ganciclovir } & & & $\begin{array}{c}<225 \mathrm{mg} \\
\text { ndividualized dose }\end{array}$ & ............ & .......... & \multirow{6}{*}{$\begin{array}{l}250 \mathrm{~mL} \\
0.9 \% \mathrm{NaCl}\end{array}$} \\
\hline & & & ....................... & & $225 \mathrm{mg}-274 \mathrm{mg}$ & 250 & ........................... & \\
\hline & & & ........................ & & $275 \mathrm{mg}-324 \mathrm{mg}$ & 300 & ............................... & \\
\hline & & & ....................... & & $325 \mathrm{mg}-374 \mathrm{mg}$ & 350 & ............................ & \\
\hline & & & ....................... & & $375 \mathrm{mg}-425 \mathrm{mg}$ & 400 & .............................. & \\
\hline & & & ............... & & $\begin{array}{c}>425 \mathrm{mg} \\
\text { ndividualized dose } \\
\end{array}$ & $\cdots \cdots \cdots \cdot$ & (............. & \\
\hline \multicolumn{3}{|c|}{ Date:_-_-_ Signature physician:............ } & 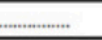 & & \multicolumn{4}{|l|}{ Date:_-_-_- } \\
\hline
\end{tabular}

Figure 1 The combined calculation, prescribing and order form for GV preparations after implementation of the dose-banding scheme.

The aim of this study was to evaluate the feasibility of DB for the prescribing of GV infusion solutions in a single unit form and to investigate the microbiological stability of automatically prepared ready-to-use GV infusion bags by media-fills and sterility tests.

\section{METHODS}

Retrospective analysis of patient individual GV preparations Individually dosed GV preparations were retrospectively analysed over an 8-month period (January to August 2015) regarding the potency of prepared doses and the frequency of preparation. The ranges of the most frequently prescribed GV doses were identified. Likewise, after the introduction of the DB scheme, the frequency of prescription of standard and individualised GV doses was analysed over a period of 8 months (September 2015 to April 2016). Data were retrieved from the preparation software Zenzy (Dr Heni Software GmbH, Germany) which was at that time installed in the cytotoxic drug preparation unit of the pharmacy department.

\section{Development of the dose-banded prescribing scheme}

According to the 'target dose' banding scheme initially four bands and the corresponding standard doses of GV were calculated by the most often prescribed doses and body weight calculations. Each standard dose was defined as the midpoint of the band, resulting in a maximum $\pm 10 \%$ variance from the individually

\begin{tabular}{llll}
\hline Table 1 & Characteristics of the target dose-banding scheme for GV \\
\hline $\begin{array}{l}\text { Target GV dose } \\
\text { [mg/kg body } \\
\text { weight] }\end{array}$ & $\begin{array}{l}\text { Proposed GV } \\
\text { standard dose } \\
(\mathbf{m g})\end{array}$ & $\begin{array}{l}\text { Proposed GV } \\
\text { band }(\mathbf{m g})\end{array}$ & $\begin{array}{l}\text { Maximum variance } \\
\text { from individual dose } \\
{[\mathrm{mg}(\%)]}\end{array}$ \\
\hline $250 / 50$ & 250 & $225-274$ & $25( \pm 10.0)$ \\
\hline $300 / 60$ & 300 & $275-324$ & $25( \pm 8.2)$ \\
\hline $350 / 70$ & 350 & $325-374$ & $25( \pm 7.0)$ \\
\hline $400 / 80$ & 400 & $375-425$ & $25( \pm 6.2)$ \\
\hline
\end{tabular}

prescribed dose (table 1). Prescribing physicians should calculate the patient individual $\mathrm{GV}$ dose by the body weight and $\mathrm{eCrCl}$, select the adequate band and thereby the standard dose. An excel sheet was designed as an electronic or pre-printed prescribing and order form (figure1).

\section{Aseptic preparation of standardised GV infusion bags in series and quality control}

GV standard doses $(250 \mathrm{mg}, 300 \mathrm{mg}, 350 \mathrm{mg}, 400 \mathrm{mg}$ ) were prepared in prefilled polyolefin infusion bags containing a nominal volume of $250 \mathrm{~mL} 0.9 \% \mathrm{NaCl}$ vehicle solution (Freeflex, Fresenius Kabi, Germany). A series of 10 infusion bags per standard dose was aseptically prepared with the robotic system APOTECAchemo (see figure 2, manufactured by Loccioni Group, Italy). Infusion bags were labelled, single packed in plastic bags and heat-sealed. Each series was identified by a 'lot number' and stocked under refrigerated storage conditions in the pharmacy department up to 4 weeks.

According to the standard procedure, sterility tests were carried out by using a rapid microbiological method. ${ }^{10}$ One aliquot amounting to $2 \mathrm{~mL}$ and one amounting to $8 \mathrm{~mL}$ was aseptically withdrawn from two randomly collected preparations of a series of 10 and transferred into an aerobic (BD BACTEC Peds Plus Aerobic medium, BD GmbH, Germany) or anaerobic (BD BACTEC Plus Anaerobic medium, BD GmbH, Germany) blood culture bottle. The media were incubated for 14 days at $38{ }^{\circ} \mathrm{C}$ in an automated $\mathrm{CO}_{2}$ fluorescent detection system (BD BACTEC 9240 Automated Blood Culture System, BD GmbH, Germany) for microbial growth detection.

\section{Media-fill simulation tests}

The aseptic preparation of standardised GV infusion bags was simulated by using sterile tryptic soy broth (TSB) according to the Ph. Eur. 9/2.06.01.00. The preparation of 10 infusion bags in a series was simulated using the robotic system APOTECAchemo. Media fills were performed on five consecutive days 

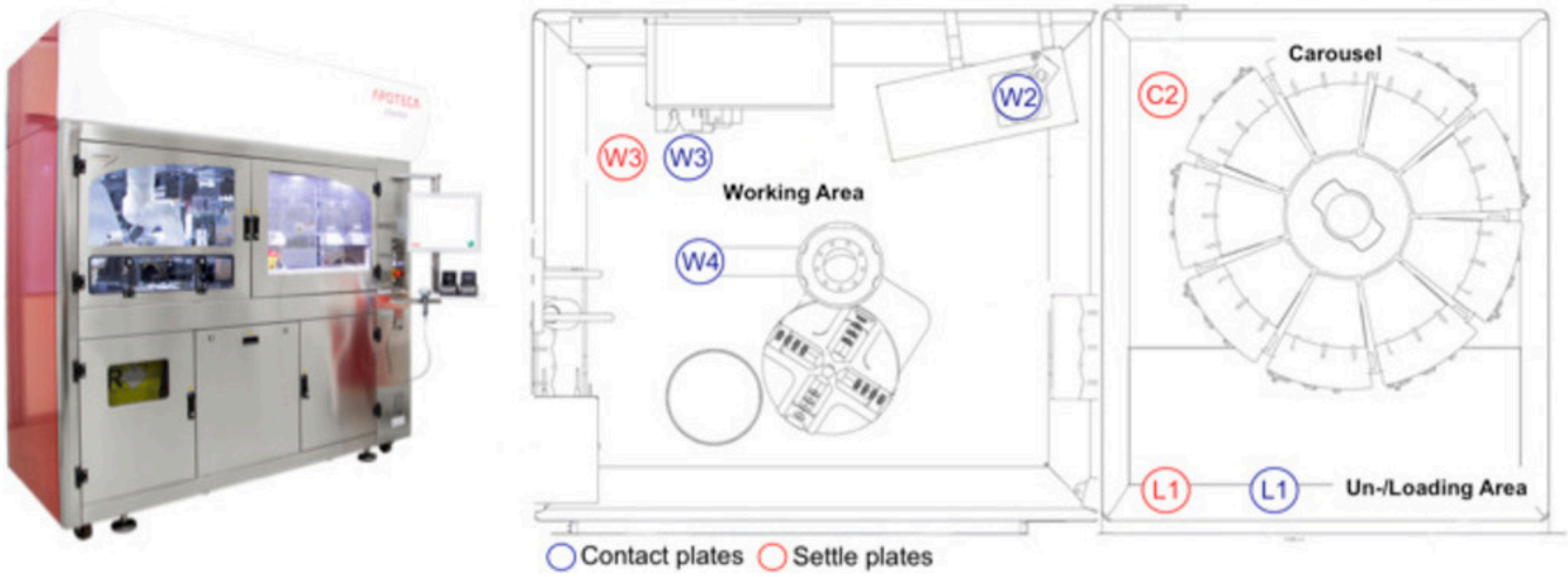

Figure 2 Picture of the APOTECAchemo (Loccioni Group, Italy) robot and graphical scheme of the locations determined for environmental monitoring with settle plates and contact plates. (L1: loading area; C2: carousel area; W2: balance; W3: surface under the dosing device; W4: gripper of the robotic arm).

(10 preparations per day, Monday to Friday) by a trained operator at the end of the working day.

Purchased vials containing $50 \mathrm{~mL}$ pre-prepared double strength TSB (BD Tryptic Soy Broth double strength, Germany, LOT 7178431, expiration date 02/07/2018), prefilled $250 \mathrm{~mL}$ $0.9 \% \mathrm{NaCl}$ polyolefin infusion bags (Freeflex Fresenius Kabi, Germany, LOT 82LC653304, expiration date 02/2020), and $50 \mathrm{~mL}$ single-use syringes (Drug Compounding Dosing Device ASN-50, Loccioni Humancare, Italy, LOT 170407, expiration date 03/2022) were loaded in the carousel of APOTECAchemo. After automated withdrawal of the superfluous vehicle solution from the infusion bags, in total $125 \mathrm{~mL}$ of TSB were withdrawn from the $50 \mathrm{~mL}$ vials and injected into the infusion bag using a $50 \mathrm{~mL}$ syringe. The final volume in the infusion bag amounted to $250 \mathrm{~mL}$ (125 mL TSB $+125 \mathrm{~mL}$ vehicle solution). In total, 50 media-fill products were prepared by using 125 vials nominally filled with $50 \mathrm{~mL}$ TSB and 50 infusion bags.

Before starting the preparation process, the outer surface of each vial was disinfected by immersion in a disinfectant solution (Terralin, Schülke\&Mayr GmbH, Germany). The surface of the rubber stoppers of each vial, as well as the injection port of each infusion bag were wiped with Perform advanced Alcohol EP (Schülke\&Mayr GmbH, Germany) in the loading area of APOTECAchemo and inserted in the carousel. After preparation and unloading, the media-fill products were labelled, single packed into plastic bags, heat-sealed and incubated.

Incubation and analysis - The media-fill products were incubated over 2 weeks according to Ph. Eur. 9/2.06.01.00 and stored for 12 weeks (maximum intended storage interval) at room temperature $\left(20^{\circ} \mathrm{C}-25^{\circ} \mathrm{C}\right)$. In order to suspend microorganisms adhering at surfaces and ensure contact with all surfaces, the media-fill products were gently mixed twice per week during the storage period. All samples were visually inspected for turbidity by the unaided eye after 2, 4, 8, 10 and 12 weeks.

Growth promotion test - The purchased TSB vials were accompanied by a certificate, which documented that growth promotion tests were accomplished for the batch. In addition, after 4 weeks of incubation, growth promotion tests of the media fills were performed. Two samples per production day were randomly collected and, overall, 10 media-fill products were inoculated with S. epidermidis KH6 (obtained from a patient sample) or S. aureus ATCC6538 suspensions. Each bacteria strain was suspended in PSB (phosphate buffer solution), adjusted to $10^{3}$ colony-forming units $(\mathrm{CFU}) / \mathrm{mL}$, and used to inoculate five samples. The inoculation was performed by adding $2.5 \mathrm{~mL}$ of bacteria suspension to each infusion bag filled with $250 \mathrm{~mL}$ growth medium in order to achieve a final concentration of $10 \mathrm{CFU} / \mathrm{mL}$, i.e. $2500 \mathrm{CFU} /$ infusion bag. The inoculated samples were incubated for 2 weeks at room temperature and visually inspected for turbidity every day. Preparation of the bacteria suspensions and inoculation were carried out at the Institute of Medical Microbiology and Hygiene, University Medical Centre Mainz (Germany).

\section{Environmental monitoring}

During the media fill simulation tests, airborne contamination was monitored by positioning settle plates (CASO-Agar, heipha Dr Müller GmbH, Germany, LOT880701, expiration date 13/01/2018) at three predefined locations of the APOTECAchemo, see figure 2), that is, loading area (L1), carousel area (C2) and working area (W3) over a 4-hour interval, each.

At the end of each production day, microbial surface contamination was tested with contact plates (CASO-Abklatschagar Tryptic Soy Contact Agar, heipha Dr Müller GmbH, Germany, LOT 919506, expiration date 23/02/2018). The sampling locations corresponded to the surface of the loading area (L1), surface of the balance (W2), single-use mat under the dosing device (W3) and the gripper of the robotic arm (W4) (see figure 2).

In addition, fingerprints were performed from gloved fingertips and thumbs of both hands by pressing on CASO-Contact plates Tryptic Soy Contact Agar tryptic soy (details given above) for at least $5 \mathrm{~s}$ at the end of a $20 \mathrm{~min}$ glove-wearing period. Fingerprints were collected once during each media-fill test.

\section{Sterility test of standard GV infusion bags}

A series of $10 \mathrm{GV}$ infusions bags containing $250 \mathrm{mg}$ of $\mathrm{GV}$ (Ganciclovir HEXAL, Hexal AG, Holzkirchen, Germany, LOT GK7722, expiration date 31/08/2019; Freeflex, Fresenius Kabi, Germany, LOT 82KM653305, expiration date 30/11/2019) was aseptically prepared and stored under refrigeration $\left(2{ }^{\circ} \mathrm{C}-8{ }^{\circ} \mathrm{C}\right)$ for 12 weeks. After the storage period, sterility tests were performed according to the Ph. Eur. 9/2.06.01.00 by a certified laboratory (Labour L+S AG, Bad Bocklet, Germany). From each 

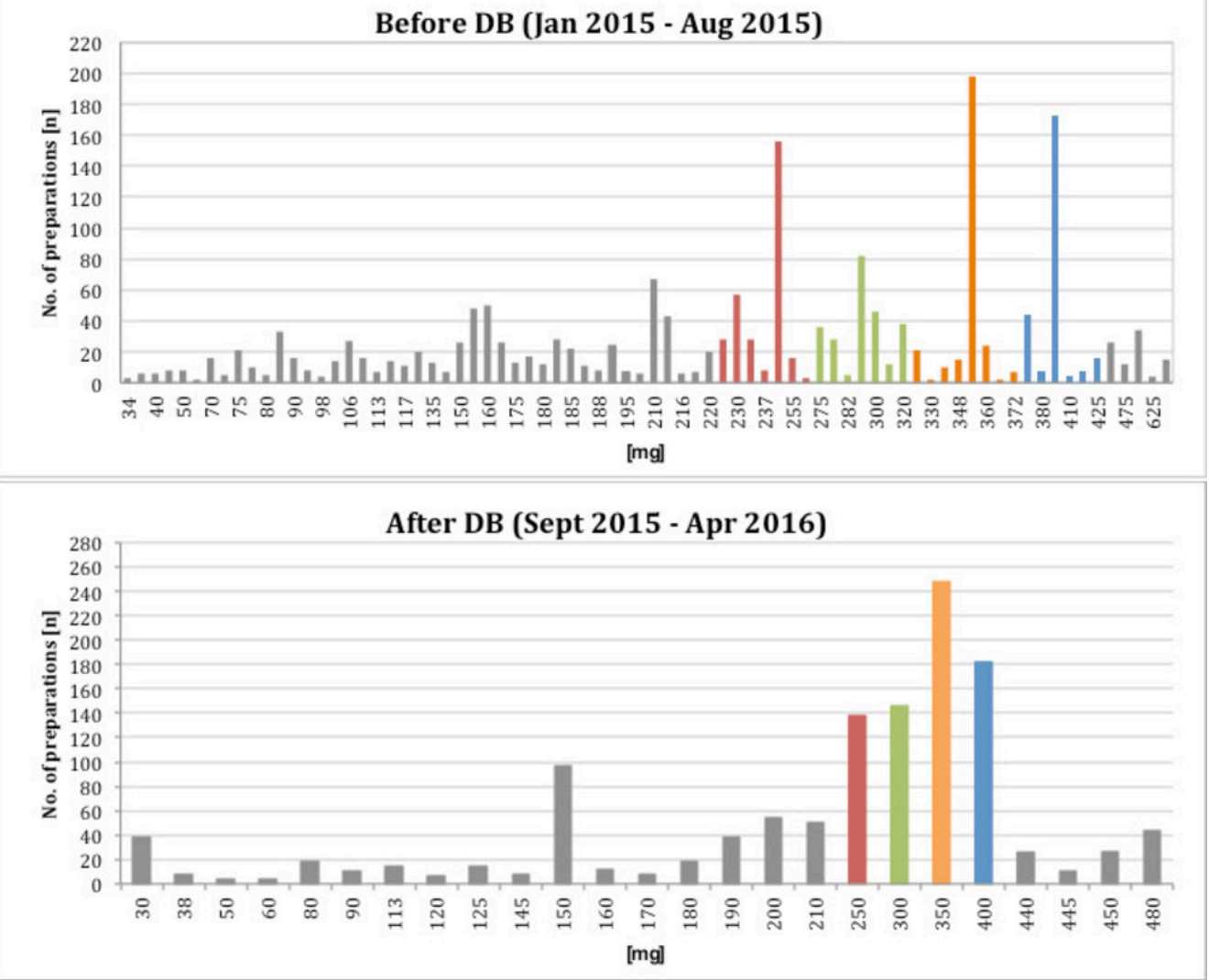

Figure 3 Potency of prepared doses and frequency of preparation before and after implementing the DB scheme.

of the $10 \mathrm{GV}$-infusion bags, $50 \mathrm{~mL}$ were filtered via mixed cellulose esters (MCE) membranes (nominal pore size of $0.45 \mu \mathrm{m}$ ) using Steritest ${ }^{\mathrm{TM}}$ EZ device (Merck KGaA, Germany). Filter membranes were incubated with soya-bean casein digest broth (SCD) for aerobic bacteria and fungi and fluid thioglycollate medium (FTM) for aerobic, micro-aerophilic, and anaerobic bacteria. SCD and FTM were incubated for 14 days at $20^{\circ} \mathrm{C}-$ $25^{\circ} \mathrm{C}$ and $30^{\circ} \mathrm{C}-35^{\circ} \mathrm{C}$ respectively. The media were examined for macroscopic evidence of microbial growth at regular intervals and at the end of the incubation period.

Growth promotion tests were performed by inoculation of the media with challenge microorganisms. The microorganisms used were C. sporogenes and B. subtilis for FTM and SCD respectively. After inoculation, the media got incubated for 5 days at room temperature and visually inspected for turbidity every day.

\section{RESULTS}

\section{Evaluation of the dose-banding scheme}

Before implementing the DB scheme, a total of 1886 readyto-use GV infusion bags corresponding to 76 different doses were prepared during an 8 months period. During the 8 months period following the implementation of the DB scheme, about $60 \%$ of the 1225 prescribed doses were covered by the of four standardised preparations. The number of different doses was reduced from 76 to 29 (25 individual and four standard doses). Patient specific doses had to be prepared for patients with body weight $>85 \mathrm{~kg}$ (single dose $>425 \mathrm{mg} \mathrm{GV}$ ) and patients suffering from renal insufficiency or children (single dose $<225 \mathrm{mg} \mathrm{GV}$ ) (see figure 3). Based on these calculations and agreement of the prescribing physicians a specific calculation, prescribing and order form for GV therapies was implemented. The form is shown in figure 1 . It can be used electronically or filled manually in a printed version.

\section{Media-fill simulation tests}

None of the 50 media-fills simulating the automated preparation of standardised GV infusion bags showed turbidity after the incubation period of 2 weeks and up to a storage period of 12 weeks indicating the absence of microorganisms. All products remained clear and light-amber solutions without colourchange. Of note, the growth promotion tests of the media fills performed after 4 weeks of storage, indicated reliability. The inoculated strains (S. epidermidis, S. aureus) caused turbidity in all samples already after 5 days of incubation and till to the end of the 2 weeks observation period (see table 2).

\section{Environmental monitoring}

The results of the environmental monitoring test performed in parallel to the media-fill simulation tests are presented in table 3. In the carousel area and the working area of the APOTECAchemo robot, the number of CFUs counted on settle/contact plates were below the limits set for EU-GMP Grade A zones $(<1 \mathrm{CFU} /$ plate). However, in the loading area, on average four CFUs were detected on settle plates and 12 CFUs on surface contact plates. The very high numbers of CFUs on settle plates and contact plates observed on day 1 of testing can be categorised as outliers. Otherwise the number of CFUs observed on day 2 to 5 in the loading area are acceptable.

\section{Sterility test}

Pooled sterility tests of $10 \mathrm{GV}$ infusion bags prepared in the APOTECAchemo revealed sterility. Aerobic and anaerobic media 
Table 2 Results of the media-fill simulation tests during automated preparation in APOTECAchemo and visual inspection after 2, 4, 8, 10, and 12 weeks of incubation

\begin{tabular}{|c|c|c|c|c|c|c|c|c|}
\hline \multirow{2}{*}{$\begin{array}{l}\text { Day } \\
\text { (No. of media fills) }\end{array}$} & \multicolumn{5}{|l|}{ Turbidity } & \multicolumn{2}{|c|}{$\begin{array}{l}\text { Number of media fills inoculated after } \\
4 \text { weeks storage }\end{array}$} & \multirow{2}{*}{$\begin{array}{l}\text { Turbidity } \\
\text { After } 2 \text { week }\end{array}$} \\
\hline & After 2 weeks & After 4 weeks & After 8 weeks & After 10 weeks & After 12 weeks & S. epidermidis KH6 & S. aureus ATCC 6538 & \\
\hline Day 1 (01-10) & None & None & None & None & None & 1 & 1 & All \\
\hline Day $2(11-20)$ & None & None & None & None & None & 1 & 1 & All \\
\hline Day 3 (21-30) & None & None & None & None & None & 1 & 1 & All \\
\hline Day 4 (31-40) & None & None & None & None & None & 1 & 1 & All \\
\hline Day 5 (41-50) & None & None & None & None & None & 1 & 1 & All \\
\hline
\end{tabular}

remained clear during the incubation period. The microorganisms selected for the growth promotion tests (C. sporogenes and B. subtilis) caused turbidity after 2 days of incubation.

\section{DISCUSSION}

\section{Implementation of the dose-banding scheme}

DB of cytotoxic preparations is not yet very common in Germany. The reason is that in the past most antineoplastic drugs were investigated in clinical trials in patient individual doses calculated by the body surface area (BSA). Although, the evidence of BSA-related dosing is meanwhile questioned, the dosing method is still carried out in accordance with the clinical trials. Thereby the workload of centralised cytotoxic preparation units in pharmacies is increasing and potentially the risk of compounding errors. ${ }^{11}$ To optimise the capacity planning of our cytotoxic preparation unit, we considered dose DB of the antiviral drugs and chose GV to start with. GV qualifies for DB by the high number of preparations, the long duration of treatment (at least 2 weeks) with twice and once daily dosing, and proven long-term physicochemical stability of the ready-to-administer infusion bags. 91213

The target DB scheme was chosen for the calculation of standard doses and the bands. In accordance with the retrospective analysis of nearly 2,000 BSA-based patient individual preparations, four standardised infusion bags were defined. The aim was to develop single unit doses with acceptable variance between the calculated patient individual dose and the standard dose. Additional manipulations on the ward to achieve the banded dose or combination of multiple infusions should be avoided. For antineoplastic drugs in general, a variance of $5 \%$ and for monoclonal antibodies the variance of $10 \%$ between the prescribed dose and the banded dose is accepted clinical practice in the UK. ${ }^{4}$ In our case, the dose variance amounted to minimal $6.2 \%$ and maximum $10 \%$ for the different bands. The proposed dose bands were agreed by the medical staff, because of the broader therapeutic window of GV compared with antineoplastic drugs and the approved dose variance of 20\% (5 mg/ $\mathrm{kg}$ or $6 \mathrm{mg} / \mathrm{kg}$ ) during maintenance treatment. ${ }^{1}$ The retrospective analysis after the introduction of DB showed that the number of GV doses $<225 \mathrm{mg}$ was increasing. Therefore, another band (190-224 mg) and the corresponding standard GV infusion bag with $210 \mathrm{mg}$ was established.

DB enables the preparation of standard infusion bags in series and as stock. Quality control testing, such as quantitative analysis of GV and sterility tests can be done prior to administration. ${ }^{14}$ In our setting the automated preparation of the $\mathrm{GV}$ standard doses is more accurate and less error-prone than manual preparation. ${ }^{15-19}$ Dosing accuracy of the robotic system is verified by gravimetric control of the measured volume and automated documentation of the deviation rate from the target value. The deviation limits were set at $\pm 5 \%$ for the GV preparations. Barcode recognition and photographic recognition of the source products ensure the identity of the brand products used. ${ }^{20}$ Since in-process controls and process documentation are given, parametric release is acceptable.

Reconstituted and diluted GV infusion solutions are known to be physico-chemically stable over prolonged periods. Parasrampuria et al $^{12}$ showed that $\mathrm{GV}$ admixtures $(0.9 \% \mathrm{NaCl}, 5 \%$ dextrose vehicle solution) of the concentration 1 and $5 \mathrm{mg} / \mathrm{mL}$ are stable for at least 35 days at room temperature or under refrigeration. Phaypradith et $a l^{13}$ reported stability of $\mathrm{GV}$ for at least 1 year at $-20^{\circ} \mathrm{C}, 80$ days at $4^{\circ} \mathrm{C}$ and 1 week at room temperature (concentration from 0.004 to $7 \mathrm{mg} / \mathrm{mL}, 0.9 \% \mathrm{NaCl}$ vehicle solution, polypropylene syringes or PVC infusion bags). In a recent study, the stability of GV infusions (concentration from 0.25 to $5 \mathrm{mg} / \mathrm{mL}, 0.9 \% \mathrm{NaCl}$ vehicle solution) was shown to be at least 185 days stored in polypropylene infusion bags or syringes either at room temperature or under refrigeration. ${ }^{9}$ Initially we planned a 12 -week storage period under refrigeration. Referring to the recently published stability data we switched to room temperature storage because of limited refrigerator capacity and more convenient handling.

However, when the beyond-use dates of ready-to-use preparations are defined, microbiological stability is also to be taken into

Table 3 Airborne and surface contamination during automated media-fill simulation tests in the APOTECAchemo over 5 days

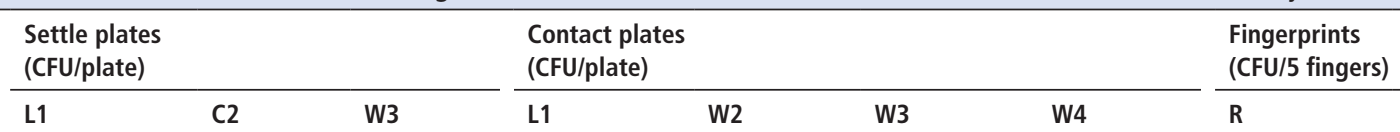

\begin{tabular}{|c|c|c|c|c|c|c|c|c|c|}
\hline & & & & & & & & \\
\hline Position & L1 & C2 & W3 & L1 & W2 & W3 & W4 & $\mathbf{R}$ & L \\
\hline Day 1 & 15 & 3 & 0 & 57 & 0 & 0 & 0 & 11 & 3 \\
\hline Day 2 & 2 & 0 & 0 & 2 & 0 & 0 & 0 & 0 & 0 \\
\hline Day 3 & 0 & 0 & 0 & 0 & 0 & 0 & 0 & 0 & 0 \\
\hline Day 4 & 5 & 0 & 0 & 1 & 0 & 0 & 0 & 5 & 0 \\
\hline Day 5 & 0 & 0 & 0 & 0 & 0 & 0 & 0 & 4 & 1 \\
\hline Mean & 4 & 1 & 0 & 12 & 0 & 0 & 0 & 4 & 1 \\
\hline
\end{tabular}

CFU, colony forming unit. L1: loading area, C2: carousel, W2: balance, W3: surface beneath the dosing device, W4: gripper of the robotic arm, R: right hand, L: left hand. 
account. ${ }^{21} 22$ Sterility and the absence of microorganisms depend on the quality of aseptic procedure and the growth supporting characteristics of the products. In previous growth promotion tests we were able to show, that microorganisms could subsist in solutions of cytotoxic and non-cytotoxic drugs, and proliferate when transferred to proper growth media. ${ }^{23-25}$ However, during these tests the GV samples showed moderate bacteriostatic and antifungal activity. ${ }^{25}$ There is no preservative contained in the $\mathrm{GV}$ formulation, but the alkaline $\mathrm{pH}$ value might contribute to the growth inhibition of microorganisms.

According to the guidelines for Good Aseptic Preparation Practice in pharmacy departments, ${ }^{10} 26$ the validation of the aseptic procedures should be done by simulating the preparation process with nutrient media (media fills) and environmental monitoring. Extensive tests by simulating the filling of $50 \mathrm{~mL}$ syringes with media in the APOTECAchemo robot revealed sterility of the test products. ${ }^{27}$ In addition, media-fill tests are performed on a regular basis demonstrating the adequacy of the existing aseptic conditions and procedures. Additional media-fill tests were performed to simulate the preparation of GV standard infusions in series by the robot APOTECAchemo. The preparation process of standardised products in pre-filled infusion bags was imitated as closely as possible. All critical steps were included, except the reconstitution of the powder. Simultaneous environmental monitoring revealed in elevated numbers of CFUs in the loading area of the robot and on the fingerprints of the operator on Day 1. This was most probably caused by using media vials bearing a high bioburden on the outer surface of the phials. We made this observation already in the past and requested intensive cleaning and disinfection of the vials. From time to time we recognise such outliers. These observations emphasise the importance of intensive cleaning and disinfection after performing media-fill tests.

The results of supplemental sterility tests of GV standard infusions confirmed the absence of viable microorganisms in the final products. As the tests were performed after 12 weeks' storage, these findings confirm that the storage conditions $\left(2{ }^{\circ} \mathrm{C}-8^{\circ} \mathrm{C}\right)$ and the secondary packaging (heat-sealed plastic bags) ensure maintained sterility of the final products over extended storage periods.

Sterility of the GV standard infusion bags is routinely checked by rapid microbiological methods. Tests are performed for each series of GV products as described above in the Methods section. Results of routine simulation tests and ongoing environmental monitoring by microbiological methods are considered, when a $\mathrm{GV}$ series is released.

Overall, the study proved feasibility and a positive impact of DB for GV preparations in clinical practice. After the introduction of DB, the number of patient individual doses decreased drastically. Meanwhile we stock standard GV infusion bags on the wards. By this measure CMV treatment can be started immediately at any time. Furthermore, the DB scheme and preparation method was applied to foscarnet preparations.

\section{CONCLUSIONS}

A target DB scheme for prescribing and centralised preparation of standard GV infusion bags and patient-specific doses at the extremes of the dose-band range has been successfully implemented. Feasibility and practicality of a specific excel-based form for the calculation, dose rounding and ordering of GV infusions were given. With four and, late,r five standard infusion solutions to be administered as single unit doses, acceptable variances of the dose bands were achieved. Microbiological tests of automatically in series prepared GV infusion bags revealed an adequate sterility level and a well-controlled aseptic procedure. The sterility was maintained over extended incubation and storage periods, thereby encouraging extended beyond-use dating up to 12 weeks. The same DB concept is applicable to other antiviral drugs, for example, foscarnet.

\section{What this paper adds}

What is already known on this subject

- The implementation of a DB scheme and dose standardisation facilitate the optimisation and the capacity of pharmacybased, centralised cytotoxic drugs preparation units, especially those with considerable daily workload.

- Ganciclovir infusion solutions are known to be physicochemically stable over prolonged periods.

- Automated preparation with robotic systems ensure adequate sterility level, a well-controlled aseptic procedure, automated in-process controls and automated process documentation.

What this study adds

- A feasible and practicable DB scheme for prescribing and preparing the antiviral GV.

- Automated aseptic preparation of infusion bags in series by using a robotic system.

- Extended beyond-usage date (up to 12 weeks) of automatically prepared infusion bags containing GV.

- The method analysed can be applicable to other antiviral drugs for parenteral administration.

Acknowledgements We are grateful to the Institute of Medical Microbiology and Hygiene, University Medical Centre Mainz and the technicians of our Pharmacy Departments for technical support.

Contributors IK and MF carried out the experiment and wrote the manuscript.

Funding The authors have not declared a specific grant for this research from any funding agency in the public, commercial or not-for-profit sectors.

Competing interests None declared.

Provenance and peer review Not commissioned; externally peer reviewed.

\section{ORCID iD}

Matteo Federici http://orcid.org/0000-0003-1537-7014

\section{REFERENCES}

1 European Medicines Agency. Cymevene: Summary of products characteristics. London, United Kingdom: European Medicines Agency.

2 Connor T, MacKenzie B, Debord D, et al. NIOSH list of antineoplastic and other hazardous drugs in healthcare setting. 2016. https://www.cdc.gov/niosh/topics/ antineoplastic/pdf/hazardous-drugs-list_2016-161.pdf

3 Plumridge RJ, Sewell GJ. Dose-banding of cytotoxic drugs: a new concept in cancer chemotherapy. Am J Health Syst Pharm 2001;58:1760-4.

4 Polwart C. Williamson S. Guidelines for the dose-banding of cancer chemotherapy. Version 2.0. 2015. http://www.necn.nhs.uk/wp-content/uploads/2016/01/NECNdose-banding-guidelines-version-2.0-Nov-15.pdf

5 Kaestner S, Sewell G. Dose-banding of carboplatin: rationale and proposed banding scheme. J Oncol Pharm Pract 2007;13:109-17.

6 Chatelut E, White-Koning ML, Mathijssen RH, et al. Dose banding as an alternative to body surface area-based dosing of chemotherapeutic agents. Br J Cancer 2012;107:1100-6

7 White-Koning M, Osborne C, Paci A, et al. Investigating the potential impact of dose banding for systemic anti-cancer therapy in the paediatric setting based on pharmacokinetic evidence. Eur J Cancer 2018:91:56-67.

8 Reinhardt H, Trittler R, Eggleton AG, et al. Paving the way for dose banding of chemotherapy: an analytical approach. J Nat/ Compr Canc Netw 2017;15:484-93.

9 Guichard N, Bonnabry P, Rudaz S, et al. Long-term stability of ganciclovir in polypropylene containers at room temperature. J Oncol Pharm Pract 2017:10

10 ResearchGate. ADKA Guideline to aseptic preparation and quality control of ready-toadminister parenterals. Krankenhauspharmazie 2013;34:93-106. 
11 Goldspiel B, Hoffman JM, Griffith NL, et al. ASHP guidelines on preventing medication errors with chemotherapy and biotherapy. Am J Health Syst Pharm 2015;72:e6-35.

12 Parasrampuria J, Li C, Stelmach A, et al. Stability of ganciclovir sodium in 5\% dextrose injection and in $0.9 \%$ sodium chloride injection over 35 days. Am J Hosp Pharm 1992;49:116-8.

13 Phaypradith S, Vigneron J, Perrin A, et al. Stability of dilute solutions of ganciclovir sodium (cymevan) in polypropylene syringes and PVC perfusion bags. J Pharm Belg 1992:47:494-8.

14 Lagarce F. Centrally prepared cytotoxic drugs: what is the purpose of their quality control? Pharm Technol Hosp Pharm 2017:2:29-33.

15 Palma E, Bufarini C. Robot-assisted preparation of oncology drugs: the role of nurses. Int J Pharm 2012:439:286-8.

16 Bufarini C, Marinozzi A, Milani M, et al. Risk assessment of cytotoxic compounding: manual vs robotic. Poster at 18th Congress of EAHP. Paris, 2013.

17 Carrez L, Bouchoud L, Fleury-Souverain S, et al. Reliability of chemotherapy preparation processes: evaluating independent double-checking and computerassisted gravimetric control. J Oncol Pharm Pract 2017;23:83-92.

18 Yaniv AW, Knoer SJ. Implementation of an i.v.-compounding robot in a hospital-based cancer center pharmacy. Am J Health Syst Pharm 2013;70:2030-7.
19 Iwamoto T, Morikawa T, Hioki M, et al. Performance evaluation of the compounding robot, APOTECAchemo, for injectable anticancer drugs in a Japanese hospital. J Pharm Health Care Sci 2017;3:12

20 Krämer I, Raffaelli J, Spindeldreier K. Workflow and capacity analysis of the fully automated cytotoxic preparation in a hospital pharmacy department. Krankenhauspharmazie 2015;10:495-504.

21 Ricci MS, Frazier M, Moore J, et al. In-use physicochemical and microbiological stability of biological parenteral products. Am J Health Syst Pharm 2015;72:396-407.

22 Bardin C, Astier A, Vulto A, et al. Guidelines for the practical stability studies of anticancer drugs: a European consensus conference. Ann Pharm Fr 2011;69:221-31.

23 Sarakbi I, Heeb R, Thiesen J, et al. Viability of selected microorganisms in non-toxic aseptic preparations. Pharm Technol Hosp Pharm 2016;1:9-20.

24 Sarakbi I, Federici M, Krämer I. Viability of microorganisms in novel chemical and biopharmaceutical anticancer drug solutions. Eur J Parent Pharm Sci 2015;20:5-12.

25 Krämer I. Viability of microorganisms in novel antineoplastic and antiviral drug solutions. I Oncol Pharm Practice 1998;4:32-7.

$26 \mathrm{PIC/S}$ PI 010-3. Guide to good practices for the preparation of medical products in healthcare establishments. 2008. http://www.picscheme.org

27 Krämer I, Federici M, Kaiser V, et al. Media-fill simulation tests in manual and robotic aseptic preparation of injection solutions in syringes. I Oncol Pharm Pract 2016;22:195-204. 